\title{
Asociacionismo gallego y mercado del libro en la Buenos Aires del medio siglo: dos proyectos editoriales de Luís Seoane
}

\author{
Galician Associations and the Publishing Industry in Buenos Aires \\ in Mid-Century: Two Publishing Projects by Luís Seoane
}

\author{
Federico GERHARDT \\ Universidad Nacional de La Plata-Consejo Nacional de Investigaciones Científicas y Técnicas \\ Instituto de Investigaciones en Humanidades y Ciencias Sociales \\ fedegerhardt@hotmail.com
}

[recibido 01/11/2014, aceptado 26/01/2015]

\section{RESUMEN}

Análisis de dos proyectos editoriales escritos por Luís Seoane, en el contexto de crecimiento del mercado del libro argentino y desarrollo de las asociaciones gallegas de Buenos Aires. En primer lugar, el proyecto de una "Biblioteca de Autores Gallegos" entre la Editorial Losada y el Centro Gallego (1939). En segundo lugar, el proyecto para la creación de Ediciones del Centro Lucense (1950).

PALABras Clave: Historia de la edición, asociacionismo gallego en Buenos Aires, Luís Seoane, Editorial Losada, Editorial Citania.

\section{RESUMO}

Análise de dous proxectos editoriais escritos por Luís Seoane, no contexto do crecemento do mercado do libro arxentino, e o desenvolvemento das asociacións galegas de Buenos Aires. En primeiro lugar, o proxecto dunha "Biblioteca de Autores Gallegos" entre a Editorial Losada e o Centro Gallego (1939). En segundo lugar, o proxecto para a creación de Ediciones del Centro Lucense (1950).

PALABRas Chave: Historia editorial, asociacións galegas en Buenos Aires, Luís Seoane, Editorial Losada, Editorial Citania.

\begin{abstract}
Analysis of two publishing projects written by Luis Seoane, during a rise in the book market in Argentina and the development of the Galician associations in Buenos Aires. Firstly, the project of "Biblioteca de Autores Gallegos" of Losada and Centro Gallego (1939). Secondly, the project to create Ediciones del Centro Lucense (1950).
\end{abstract}

KEY WORDS: Publishing History, Galician associations in Buenos Aires, Luís Seoane, Editorial Losada, Editorial Citania.

Gerhardt, F. (2015): “Asociacionismo gallego y mercado del libro en la Buenos Aires del medio siglo: dos proyectos editoriales de Luís Seoane”, Madrygal (Madr.), 18, Núm. Especial: 457-467.

SUMARIO: 1. Exiliados gallegos en Buenos Aires. Campo editorial y asociacionismo. 2. Luís Seoane, entre Editorial Losada y el Centro Gallego. 3. De las Ediciones del Centro Lucense a la Editorial Citania. 4. A modo de conclusión: dos nudos entre los circuitos editoriales y las tramas asociativas. 5. Referencias bibliográficas. 


\section{EXILIADOS GALLEGOS EN BUE- NOS AIRES. CAMPO EDITORIAL Y ASOCIACIONISMO}

Es sabido que una de las consecuencias más duras y duraderas de la Guerra Civil española fue el exilio de una parte considerable de su población, que buscó acogida en países como Francia, México y Chile, entre otros muchos. En el caso de la Argentina, a falta de una política de estado abierta, fueron claves las gestiones de las instituciones culturales y educativas (Schwarzstein 2001: 44-162), que tuvieron como consecuencia la llegada de un número importante de intelectuales y artistas españoles exiliados. Algunos de estos gozaban de prestigio en el campo intelectual argentino -ya sea por sus anteriores visitas, por la llegada de sus libros o sus colaboraciones en la prensa periódica-, y su inserción se produjo rápidamente, contando con un público receptor. Estos exiliados -entre los que se cuentan, por ejemplo, Francisco Ayala y el autodenominado "autoexiliado" Guillermo de Torre-, junto con otros menos conocidos, se integraron en un lapso breve a algunos de los espacios de mayor prestigio del campo cultural argentino de la época, tales los suplementos de los grandes diarios como La Nación y La Prensa, y destacadas revistas como Nosotros y Sur (Zuleta 1991: 183-188, Macciuci 2011: 159-162).

Diferente es lo que sucede con otro núcleo importante de exiliados que, aunque en ocasiones encontraron espacios en que insertarse laboralmente en el campo cultural, buscaron también sus propias vías de publicación hacia comienzos de la década de los 40 , a través de la creación de revistas y la incursión en la actividad editorial en un momento particularmente propicio de la historia argentina, dentro del periodo del "auge de la industria cultural" (Rivera 1998: 94) y, más específicamente, en los inicios de la conocida como "época de oro de la industria editorial" (Diego 2006: 91), que se suele ubicar entre los años 1938 y 1955, aproximadamente. Se trata de una coyuntura favorable por el crecimiento del mercado del libro en la Argentina y por la caída de la industria editorial española como consecuencia de la Guerra Civil y la inmediata posguerra, que permitió no sólo que el libro argentino dominara el mercado interno sino también la expansión de las editoriales argentinas hacia el mercado externo (Diego 2006: 103-105). Es en este periodo cuando se afianzan y desarrollan empresas editoriales comandadas, en muchos casos, por españoles residentes en Argentina, tales los casos de Sudamericana, por Antonio López Llausás, Emecé, por Mariano Medina del Río y Álvaro de las Casas, y Losada, por Gonzalo Losada (Pochat 1991).

En el antes mencionado grupo de exiliados que buscaron sus propias vías de publicación, podría ubicarse una nómina que tendrá un papel notable en el desarrollo de la industria cultural porteña, entre los que cabe destacar las figuras de Rafael Dieste, Arturo Cuadrado, Lorenzo Varela y Luís Seoane, entre otros. En muchos casos, la trayectoria profesional en el mercado del libro porteño estará relacionada, no sólo con la ya referida situación favorable de la industria editorial argentina, sino también con el importante desarrollo de las entidades asociativas de ámbito gallego en Buenos Aires, determinado por las dimensiones de la inmigración procedente de Galicia en las dos últimas décadas del siglo XIX y, especialmente, las dos primeras del siglo XX (Rodino Lalín 1991: 290). En este sentido, cabe señalar que las asociaciones étnicas gallegas sumaban a sus funciones asistenciales, una dinámica labor cultural que cobra nuevo impulso hacia fines de la década de los 30 :

A esta evolución de las corrientes migratorias condicionadas por la situación internacional se une otro factor que va a influir fuertemente en el marco asociativo gallego: la nueva situación política surgida en el Estado español con el comienzo de la Guerra Civil, así como el posterior exilio de muchos intelectuales y políticos republicanos, que van a convertir a la República Argentina en el principal destino americano de los exiliados gallegos. (...) Muchos de estos exiliados se insertarán en el tejido asociativo gallego y lograrán una fuerte dinamización del mismo, sobre todo en el ámbito cultural, lo que convertirá a la ciudad de Buenos Aires en la capital cultural y política de esa Galicia ideal soñada por Castelao. (Fernández Santiago 2001: 182) 
En términos generales, esta tarea cultural tiene como objetivos primordiales la difusión de la cultura gallega como cultura nacional diferenciada y la promoción de una mayor comunicación entre los gallegos de la inmigración, y de estos con los de Galicia, al tiempo que busca estrechar lazos con la sociedad receptora. Para este fin, además de la organización de conferencias, cursos, exposiciones, ferias y concursos, las distintas asociaciones gallegas en Buenos Aires desarrollaron una intensa labor editorial, entendida ella en sentido amplio, es decir, tanto a través de la publicación de revistas, periódicos y boletines, como por medio de la edición de libros. Así, por ejemplo, podrían mencionarse entre muchos otros los casos del Boletín Oficial del Centro Gallego, luego rebautizado Galicia, y del se1lo Ediciones Galicia, ambos del mencionado Centro; o el periódico El Despertar Gallego -también rebautizado Galicia- y la Editorial Alborada, de la Federación de Sociedades Gallegas (Rodino Lalín 1989).

No obstante, cabe destacar que, paralelamente a estas iniciativas debidas a las instituciones asociativas gallegas, existieron, con desigual fortuna, muchos intentos editoriales particulares -en el contexto propicio ya referido- abocados a la misma empresa de difusión de la cultura gallega, promovidos muchas veces por los mismos agentes del campo cultural, estableciendo de este modo vínculos entre uno y otro circuito editorial. En este aspecto, la trayectoria profesional de Luís Seoane en el exilio constituye un caso interesante desde sus inicios.

\section{LUÍS SEOANE, ENTRE LOSADA Y EL CENTRO GALLEGO}

Como señala María Antonia Pérez Rodríguez, "Seoane empieza en Buenos Aires a sumergirse en torno al libro a partir de 1938" (2009: 111), precisamente cuando se está produciendo el llamado "despegue" (De
Sagastizábal 1995, Esposito 2010, Saítta 2004) de la industria editorial argentina, que dará inicio a su ya referida "época de oro". En ese mismo año de 1938, Seoane comienza a hacer trabajos para una de las grandes casas editoras de la Argentina, la Editorial Losada, fundada en agosto de ese mismo año.

La fundación de la Editorial Losada parte de los capitales de Gonzalo Losada, empresario español de ascendencia gallega residente en la Argentina desde 1928. Tras haberse desempeñado como director de Espasa Calpe Argentina, Losada integró el grupo fundador de la editorial, junto con Guillermo de Torre y Atilio Rossi -quienes también habían formado parte de la filial argentina de Espasa Calpe, como asesor y colaborador, respectivamente-, acompañados por Amado Alonso, Pedro Henríquez Ureña y Francisco Romero. Más tarde se sumarán a ellos Felipe y Luis Jiménez de Azúa, Lorenzo Luzuriaga, Teodoro Becú y Enrique Pérez, entre otros (Gudiño Kieffer 2010: 8, Larraz 2011: 134). A lo largo de su andadura, la Editorial Losada se caracterizó por dar cabida a los exiliados españoles, tanto en la nómina de autores que constituían su catálogo como en las diversas tareas editoriales, desde la selección y traducción de títulos hasta la maquetación y diseño (Larraz 2009, Zuleta 1999), contexto en que se encuadra la antes referida participación de Seoane.

Por otro lado, el pintor entra a trabajar en el Centro Gallego también en 1938 acompañando la entrada de los galleguistas republicanos vencedores en las elecciones. Ese mismo año se crearán las primeras comisiones de cultura, a las que se destinará un porcentaje del presupuesto total de la entidad (Fernández Santiago 2001: 187). El Centro constituía la gran asociación gallega de Buenos Aires y una de las más antiguas, que desde su ininterrumpida marcha iniciada en $1907^{1}$ había logrado construir su poder apoyada en el considerable número de inmigrantes gallegos residentes en la

\footnotetext{
${ }^{1}$ Cabe señalar que el primer Centro Gallego de Buenos Aires había surgido en 1879 y se había disuelto en medio de pugnas internas en 1892 (Rodino Lalín 1991: 290-291).
} 
ciudad (Fernández Santiago 2001: 184-189). Sobre las tareas de Seoane en el Centro Gallego, entre las que estaba la publicación periódica de la antes citada Galicia, explica Pérez Rodríguez:

O seu emprego incluía as obrigas de organizar todo tipo de actos e certames, encargarse de todas as publicacións, xestionar as relacións con outras institucións e cos medios de comunicación. No seu posto mesturábanse as funcións de relacións públicas coas de director editorial e xefe de prensa. (2007: 326)

Precisamente entre estas dos entidades diferentes, una cultural y comercial y la otra asistencial y cultural, con las que Seoane se relaciona tempranamente en la Argentina, va a situarse un plan editorial fechable en $1939^{2}$. Se trata de un "Proyecto para la elaboración de un convenio entre la Editorial Losada y el Centro Gallego de Buenos Aires", redactado por el propio Seoane, por el cual la "Editorial Losada S.A. crearía una biblioteca especial denominada, por ejemplo, 'Biblioteca de Escritores Gallegos' auspiciada por el Centro Gallego de Buenos Aires", de acuerdo con su primer apartado. Aunque breve, el proyecto es claro en cuanto a las condiciones del convenio propuesto. El plan editorial comprende en principio el periodo de un año, más precisamente, 1940. Según las cláusulas $2^{\mathrm{a}}$ y $9^{\mathrm{a}}$ :

El compromiso inicial se haría para 12 libros que se publicarían a razón de uno por mes, sin perjuicio de que continuaran las publicaciones siempre a base de 12 libros por compromiso, o, lo que es lo mismo, por periodos de un año. (...) De llegarse a un acuerdo, la biblioteca podría iniciarse en el mes de enero de 1940.

En el mismo documento, se fijan las obligaciones y derechos económicos de cada una de las partes: $3^{\circ}$ Para que esta biblioteca fuera factible el Centro Gallego tendría que facilitar a la Editorial Losada S.A. no menos de 1.500 suscripciones para cada serie de 12 libros, corriendo por cuenta del Centro la labor de suscripción, cobranza, etc.

$7^{\circ}$ La Editorial Losada S.A. a modo de contribución por la labor cultural que desarrolla el Centro Gallego, le abonaría el 30\% del importe de las suscripciones, suma que el Centro dedicaría a funciones culturales tales como adquisición de ejemplares de la biblioteca, libros para la biblioteca del Centro, etc.

Pero al mismo tiempo, junto a estas condiciones económicas y tan importantes como ellas, se brindan detalles con respecto a ciertos parámetros de gestión y selección en la constitución de la Biblioteca planificada, los cuales dejan en evidencia el propósito de difusión de la cultura gallega, al que ya se ha hecho referencia anteriormente. Es así que los incisos quinto y sexto proponen:

$5^{\circ}$ La dirección literaria y artística de la biblioteca sería compartida por la Editorial y una persona nombrada especialmente por el Centro Gallego.

$6^{\circ} \mathrm{La}$ Editorial procuraría que todas las personas que por cualquier motivo hubieran de intervenir en la preparación de la biblioteca, fueran gallegas o de tal origen, con objeto de dar a aquélla un carácter marcadamente galleguista.

Por último, cabe destacar uno más de los apartados incluidos por Seoane en el proyecto, referido al precio de los ejemplares, en que prevé un problema que en la década siguiente alcanzará efectivamente a la industria editorial argentina, y sobre el que entonces llamará la atención Gonzalo Losada en su intervención "Los problemas del libro" (De Sagastizábal 1995: 116-117). La cuarta cláusula consigna:

\footnotetext{
${ }^{2}$ Tanto este proyecto editorial como el otro abordado en el presente trabajo (Ediciones del Centro Lucense, vid. infra), así como las cartas citadas en el desarrollo de este, obran en el archivo de la Fundación Luís Seoane (A Coruña). Agradezco a Carmela Montero, responsable del Área de Documentación, por la ayuda brindada en el acceso al material.
} 
$4^{\circ} \mathrm{El}$ precio de cada volumen se fijaría provisionalmente en $\$ 2.50 \mathrm{~m} / \mathrm{n}$, pero la Editorial quedaría facultada para aumentar este precio si, cosa segura, la prolongación de la guerra europea, al originar el aumento del costo de producción por encarecimiento de materias primas, mano de obra, etc. determinara asimismo el encarecimiento del libro.

Podrían proponerse diferentes conjeturas que expliquen el hecho de que finalmente no viera la luz la Biblioteca de Autores Gallegos proyectada por Luís Seoane para la Editorial Losada. Lo cierto es que esta tentativa frustrada no le va a impedir sacar a la calle colecciones de temática y/o autores gallegos. Es así que, ya desde 1940 y hasta 1942, periodo en que desempeña diversas tareas relacionadas con el mundo del libro en la ya mencionada editorial Emecé, Luís Seoane dirige dos colecciones dedicadas a temas y escritores gallegos. "Dorna", destinada a la poesía, en el marco de la cual aparecieron obras como Rojo farol amante (1940) de Rafael Dieste, Queixumes dos pinos (1940) de Eduardo Pondal, Cantigas de Macías o namorado (1941) y el Cancionero popular gallego (1942) de José Pérez Ballesteros. Y "Hórreo", que publicó, sobre todo pero no exclusivamente, títulos de autores de los siglos XVIII y XIX, como el Padre Feijóo, F. Martín Sarmiento, E. Gil y Carrasco.

Al dejar Emecé en $1942^{3}$, junto con Arturo Cuadrado funda Seoane la editorial Nova, sello que cesa en 1947 y bajo el cual aparecen nuevamente otras dos colecciones destinadas a la literatura gallega: "Camino de Santiago", dedicada al ensayo y la narrativa, en la que verá la luz, por ejemplo, el célebre libro Historias e invenciones de Félix Muriel (1942) de Rafael Dieste; y "Pomba" -luego rebautizada "Paloma"-, dedicada a la poesía, la cual se inicia con el poemario Torres de amor (1943) de Lorenzo Varela ${ }^{4}$.

Paralelamente a la tarea desarrollada en Emecé y luego en Nova, Seoane continúa involucrándose en diversos proyectos editoriales en los que lo acompañan artistas e intelectuales gallegos como Cuadrado, Varela y Dieste, tales como la revista De Mar a Mar (1942-1943), el periódico Correo Literario (1943-1945) y el quincenario Cabalgata (1946-1948). Asimismo, continúa con sus tareas en el Centro Gallego de Buenos Aires, a las que se sumará una nueva, a partir de 1950. Ese año se funda Ediciones Galicia, sello editorial del Centro Gallego de Buenos Aires, que abre su catálogo con Danzas populares gallegas de Fernández del Riego y Las catedrales gallegas de Jesús Carro García.

Aunque existían circunstancias concretas que habían vuelto oportuna la empresa editorial, podría considerarse que, en cierta medida, Ediciones Galicia concretaba al menos en parte aquel proyecto que Seoane había concebido en convenio entre Losada y el Centro Gallego una década antes. Al respecto, afirma Pérez Rodríguez: "La editorial era un viejo anhelo del artista por el que llevaba peleando años y su nacimiento no cabe desvincularlo de la

${ }^{3}$ En relación con la causa probable de la salida de Cuadrado y Seoane de Emecé, tres son las versiones que circulan: que se negaron a editar un libro del entonces embajador de la España franquista en la Argentina, que hicieron lo propio con una novela de Camilo José Cela, y que se solidarizaron con Lorenzo Varela ante los ataques recibidos por su militancia comunista. Señala Pérez Rodríguez, tras repasar estos tres motivos probables, que a ellos "se une que eran escasas las ventas de las obras de nuestros escritores o sobre nuestra Tierra, por lo que los resultados económicos tampoco jugaban a su favor” (2009: 112). En igual sentido apunta De Diego, quien agrega ciertos detalles a esta hipótesis: "Parece ser, incluso, que la deserción de los dos gallegos de Emecé tuvo que ver con el giro de la editorial hacia la publicación de autores argentinos como Mallea y Borges, política a la que ellos se mostraban reticentes, ya que preferían continuar con la edición de textos de temática galleguista muy poco rentables" (2006: 99).

${ }^{4}$ Sobre la editorial Nova y la construcción de su catálogo en el periodo 1942-1947, véase el trabajo de Pérez Rodríguez (2013). 
exposición sobre el libro gallego patrocinada por esa entidad societaria en 1948" (2009: $115)^{5}$.

En el nuevo sello Ediciones Galicia, Seoane se va a desempeñar desde el principio en prácticamente todos los aspectos de la actividad editorial, desde la dirección hasta la difusión, pasando por el diseño, la maquetación y la impresión de los volúmenes, tareas en cuyo desarrollo entrará en conflicto con las autoridades del Centro Gallego, hasta que abandona la entidad en 1957.

\section{DE LAS EDICIONES DEL CENTRO LUCENSE A LA EDITORIAL CITANIA}

En el mismo año en que comienza su andadura Ediciones Galicia, Seoane va a redactar otro proyecto editorial que involucraría a una entidad asociativa de ámbito gallego. Se trata de un proyecto fechado en 1950, para la creación de las Ediciones del Centro Lucense de Buenos Aires, el cual había surgido en 1943 como resultado de un cambio producido dentro de la colectividad gallega en Buenos Aires durante la década de los 40, y que podría resumirse en el hecho de que nacen los centros provinciales ${ }^{6}$.

En el proyecto de Ediciones del Centro Lucense de Buenos Aires propone una empresa cuya dimensión económica no es sino el medio para alcanzar el objetivo cultural que nuevamente es la difusión de la cultura gallega: "una editorial gallega planteada con sentido comercial, de modo que su existencia sea efectiva y duradera y pueda ser de verdad útil a Galicia, en ella misma [su territorio] y en este continente". Este objetivo se refuerza en una acotación que cierra el documento:

Nota: Consideramos que el primer fondo editorial inmediato no puede ser menor a diez libros y los beneficios que puedan deducirse de su venta, deducidos los intereses del capital que se invierta y su amortización, debe invertirse en aumentar la producción editorial.

El plan anuncia tres colecciones aunque se presentan finalmente cuatro apartados dedicados a su breve descripción:

A) Ensayos, cuya serie de libros en idioma gallego y castellano podría denominarse "Colección Idacio" en homenaje al gran historiador gallego del siglo V que, con Orosio, constituye el primer aporte fundamental conocido de Galicia a la ciencia europea y ambos los primeros ejemplos de interés por el propio pueblo. Esta colección de ensayos estaría constituida por volúmenes, en general mayores de 160 páginas, dedicados a estudiar los más diversos aspectos de la cultura gallega. Bilingüe.

B) Narración, teatro, poesía. "Colección Mestre Mateo" en homenaje al gran artista medieval. Volúmenes de más de 64 páginas. Exclusivamente en idioma gallego y pueden caber en esta colección por igual libros inéditos que aquellas reediciones de libros gallegos agotados que se consideren indispensables a nuestra cultura.

C) Monografías. Serie de textos breves de 48 a 64 páginas de las cuales 8 o 16 pueden ser de reproducciones, destinados a estudios monográficos de divulgación sobre distintos aspectos de Galicia y de su cultura, destinado sobre todo a extender el conocimiento de nuestra tierra y de sus problemas en [entre] el público ageno [sic] a ella y entre los descendientes de gallegos. Esta colección, "Colección Donosiña", fundamentalmente escrita en castellano, estará destinada a propagarse por América.

D) Monumentos, arte, etc. Libros de gran formato que se editarán ocasionalmente con breve texto en gallego, castellano e inglés, destinados a divulgar algún aspecto particular de la cultura gallega. Las traducciones de otros idiomas al gallego pueden incluirse en los apartados A y B.

\footnotetext{
${ }^{5}$ El catálogo de la exposición se publicará como Libros y autores gallegos. Primera exposición organizada por el Centro Gallego de Buenos Aires. Día de Galicia de 1948, Buenos Aires.

${ }^{6}$ Coinciden en señalar este proceso asociativo de la colectividad gallega en la capital argentina estudios como los de Rodino Lalín (1991: 307), Fernández Santiago (2001: 196) o Díaz (2012: 124-125).
} 
Los fines de difusión de la editorial apuntando hacia un lectorado amplio pueden observarse sobre todo en el último apartado, donde se propone una serie trilingüe de libros, y en la "Colección Donosiña", de libros en castellano destinados a descendientes de gallegos y al público en general. Por el contrario, sólo los textos de creación literaria incluidos en la "Colección Mestre Mateo" se editarían exclusivamente en gallego. En relación con esto, resulta interesante observar los detalles que brinda el proyecto acerca de su financiación. Al respecto, se plantea la venta de tres modos. En primer lugar, por suscripción ${ }^{7}$. En segundo lugar, "en librerías de Galicia, el resto de España y América", punto sobre el que se explaya:

Para la venta en librerías puede estudiarse la concesión de la distribución de los libros a una empresa distribuidora en cuanto a América, y en cuanto a Galicia y a España encomendar su distribución, por ejemplo, a la editorial Galaxia de $\mathrm{Vigo}^{8}$, o a la Librería Monterrey ${ }^{9}$, o a otra similar de modo que el libro pueda ser bien distribuido en Galicia.

Por último, esta red de distribución comercial se completa con las redes de sociabilidad gallega que se extienden también por fuera de las fronteras argentinas, al proyectar las ventas "por medio de las entidades gallegas de $\mathrm{La}$ Habana, Nueva York, Caracas", en consonancia con lo explicitado respecto de la "Colección Donosiña" en el apartado C precitado, y proponiendo estudiar la colocación directa de los libros por medio de entidades gallegas en aquellas ciudades americanas de gran emigración gallega, como Nueva York, La Habana, Venezuela [sic] y países con monedas cuyo cambio pueda favorecer a la editorial.

Este proyecto presentado al Centro Lucense de Buenos Aires será rechazado, no obstante lo cual podrá concretarse, no sin ciertos cambios, unos años más tarde.

En 1957, el mismo año en que termina sus trabajos al frente de la ya referida Ediciones Galicia, Luís Seoane funda la Editorial Citania, empresa en la que es acompañado por Diego Díaz Dorado, del Centro Lucense, y Antonio Baltar, de la AGUEA (Asociación Gallega de Universitarios, Escritores y Artistas), entre otros (Rodino Lalín 1989: 65, Pérez Rodríguez 2009: 115). En carta del 8 de noviembre de 1957, Seoane le habla a Francisco Fernández del Riego sobre el origen y los propósitos de la nueva empresa editorial:

Citania promete ir bien. Nos costó bastante formar la sociedad anónima. Abundan entre los accionistas la gente pobre; por mi parte, además de trabajar gratis, como siempre en toda empresa gallega, invertí en ella parte de mis ahorros. Preside el directorio Perfecto López, y están agenos [sic], naturalmente, aquellos para quienes la acción cultural gallega se convirtió en hábito de discursos y tertulias y nada más.

Aunque presenta algunos cambios, en las cinco colecciones que componen el catálogo de Citania pueden advertirse, subyacentes,

${ }^{7}$ En este punto, el proyecto se explaya a través de un ejemplo detallado: "Si suponemos que un libro de 160 páginas puede costar aproximadamente sus 2000 ejemplares, $\$ 16000$, el precio de cada libro será de 8 pesos. Si este costo lo multiplicamos por tres para lograr el precio de venta al público, su resultado sería de $\$ 24$. (En los \$16 de diferencia se incluyen derechos de autor, el 10 al 15\%; descuento a la librería del 30 al $45 \%$ y gastos de administración y beneficio de la editorial.) Si al suscriptor se concede de beneficio el $20 \%$ de los 24 pesos, es decir $\$ 4.80$ por ejemplar, restan para la editorial $\$ 19.20$, lo que equivale a que 1000 suscriptores dejen de ingreso inmediato 19200 pesos, es decir 3200 más del costo de imprenta, quedando para la editorial aún el importe de la venta en librerías y directa al público de 1000 ejemplares".

${ }^{8}$ La Editorial Galaxia había sido fundada el 25 de julio de ese mismo año. El propio Seoane había seguido las circunstancias de su surgimiento a través, por ejemplo, de las cartas cruzadas con Francisco Fernández del Riego.

${ }^{9}$ Unos años después Seoane le comenta a Fernández del Riego: “Al Centro Lucense les aconsejé para que se pusieran en contacto con la librería Monterrey, para que les organice una biblioteca gallega" (carta del 7 de septiembre de 1956). 
restos del proyecto de Ediciones del Centro Lucense rechazado años antes, como sugieren los especialistas (Axeitos y Seoane 1994: 21-22). Así, por ejemplo, puede encontrarse la "Colección Mestre Mateo", dedicada a la narrativa y al teatro, aunque excluyendo a la creación poética, bajo cuyo rótulo aparecen títulos como Midas. O ángulo de pedra (1957) de Isaac Díaz Pardo, Non agardéi por ninguén (1957) de Ramón de Valenzuela, A fiestra valdeira (1958) de Rafael Dieste, Pauto do demo (1958) de Ánxel Fole y A esmorga (1959) de Eduardo Blanco Amor. Por su parte, la poesía deja su lugar en "Mestre Mateo" para tener cabida en la "Colección Herba de Namorar", en el marco de la cual se editan Os relembros. As cantigas (1959) de Emilio Pita, As cictatrices (1959) de Luís Seoane, y Pra unha terra apremida (1961) de Antón Santamarina Delgado.

También reaparece en Citania la "Colección Idacio", que incluye libros como Grandeza y decadencia del reino de Galicia (1957) de Emilio González López, y Las tortugas del Orinoco (1960) de José Mosqueira Manso. A estas tres se agregan otras dos colecciones. Por un lado, "O Dolmen de Dombate", dedicada a cuestiones culturales, en la que ven la luz, en 1958, dos volúmenes de Francisco Fernández del Riego: Galicia y nuestro tiempo. La obra de una generación y Pintura galega. Por otro lado, la "Colección Martín Sarmiento", que reúne, fundamentalmente, estudios sobre cuestiones económicas y jurídicas de Galicia, tales los casos de Sistema económico de la pesca en Galicia de Valentín Paz Andrade, El campo gallego de Cruz Gallástegui Unamuno, El sistema geológico de Galicia de Isidro Parga Pondal y El régimen jurídico de la propiedad territorial en Galicia a través de sus instituciones forales de Sebastián Martínez-Risco y Macías, todos ellos de 1958.
Por último, fuera de colección, se editó, en 1957, Poemas para mi retorno de Víctor Luis Molinari y, en 1959, Figurando recuerdos, libro de Luís Seoane que, como señala el colofón, "selecciona, entre otros, dibujos en color publicados en la revista Galicia Emigrante" y que, al igual que los demás de la editorial Citania, fue impreso en la Imprenta López ${ }^{10}$.

Este breve repaso llama la atención sobre ciertas coincidencias significativas entre el catálogo de las Ediciones del Centro Lucense, proyectado en 1950, y el catálogo construido por la Editorial Citania a partir de 1957. Queda en evidencia la pervivencia de la "Colección Idacio" $\mathrm{y}$, fundamentalmente, de la "Colección Mestre Mateo", aunque ya sin la poesía, volcada en "Herba de Namorar". En ambas, puede observarse la exclusividad del idioma gallego planteada en el proyecto de 1950, así como la posibilidad de incluir reediciones, tal el caso de A fiestra valdeira de Rafael Dieste, editada por primera vez en Santiago en 1927.

Además de estas coincidencias de catálogo, cabe señalar al menos otra similitud, en este caso relativa a la venta de los ejemplares $^{11}$. De igual modo que lo había propuesto años antes al Centro Lucense, y dirigiéndose nuevamente a la colectividad gallega, en 1957 Seoane se propone como método de venta, en primer lugar, la suscripción, partiendo incluso del mismo número de suscriptores estimado en el proyecto de $1950^{12}$. Ante la aparición del nuevo sello, expresa en su programa radial Galicia emigrante:

A Editorial Citania aspira a ter un mínimo de mil suscriptores dos seus libros. A ter na colectividade un núcleo inicial de mil homes galegos ou de orixe galega que, porque senten amor á súa estirpe e á vella nación da súa orixe, apoien esta obra de divulgación cultural que servirá

${ }^{10}$ En cuyos talleres, a su vez, se imprimían los volúmenes de la editorial Nova y los números de la revista De Mar a Mar, aludidos en las páginas previas.

${ }^{11}$ A lo que, a su vez, podría agregarse la ya referida participación, como colaborador pero también como accionista de Editorial Citania, de un dirigente del Centro Lucense de Buenos Aires como Diego Díaz Dorado.

12 Véase la nota 7. 
para engrandecer o nome de Galicia nas repúblicas americanas. Non se trata dunha empresa interesada en favorecer a este ou a outro partidista da colectividades, a un ou a outro ideal. Trátase dunha empresa que non ten máis programa que o de facer coñecer entre proprios e extraños o espiritu de Galicia. (Seoane 1989: 427)

A pesar de esta convocatoria y del entusiasmo inicial, visible en la carta a Fernández del Riego de noviembre de 1957 citada líneas arriba, en que Citania "prometía ir bien", ya el 18 de febrero de 1960, en carta a Díaz Dorado, Luís Seoane empieza a vislumbrar el fin de la empresa editorial:

Pienso en Citania sin dinero y sin aliento alguno y me da pena por Galicia, más desdichada si cabe por la desorientación de aquellos, sus hijos, como los de Buenos Aires, que podrían hacer algo por ella, pero siento orgullo de nuestro esfuerzo, el suyo, el de Lamela, Baltar, Julio Fernández, casi nadie más; Perfecto López, excelente gallego que podría hacer mucho si creyese de verdad en esta labor...

Pocos meses después, en carta del 18 de mayo, Díaz Dorado le confirma que Citania "languidece, a pesar de nuestros esfuerzos". Si bien podría atribuirse la escasa fortuna de la editorial al mismo factor al que se puede adjudicar, al menos en parte, la frustración del convenio entre Losada y el Centro Gallego, y la salida de Cuadrado y Seoane de Emecé ${ }^{13}$ y, más tarde, de Nova (Pérez Rodríguez 2013: 121), esto es, las escasas ventas cosechadas por los libros de temas y/o autores gallegos, el naufragio de la Editorial Citania se produce en un contexto diferente, cuando ya se había entrado en periodo menos favorable para la industria editorial, cuyos inicios suelen ubicarse entre los años 1956 y 1960 (Rivera 1998: 128 y ss, Getino 1995: 46, 55) ${ }^{14}$.

\section{A MODO DE CONCLUSIÓN: DOS NUDOS ENTRE LOS CIRCUITOS EDI- TORIALES Y LAS TRAMAS ASOCIA- TIVAS}

A pesar de tratarse de dos momentos puntuales, los dos proyectos revisados, la "Biblioteca de Autores Gallegos" de Losada y el Centro Gallego, por un lado, y las Ediciones del Centro Lucense, por el otro, permiten vislumbrar las dificultades que se presentaban a las iniciativas editoriales destinadas a la difusión de la cultura gallega, aun en un contexto que podría pensarse como propicio, por un lado, dadas las condiciones que determinaron la conocida como "época de oro" del mercado del libro en la Argentina, y, por otro lado, en virtud del importante desarrollo de las entidades asociativas de ámbito gallego en Buenos Aires. Asimismo, y en relación con estos dos factores, a través de ambos proyectos, aun en sus diferentes grados y tiempos de realización, podrían observarse las relaciones entre, por una parte, las empresas editoriales de la Argentina y sus vías de distribución y, por otra, las instituciones gallegas y sus redes asociativas. En este sentido, cabe señalar que los dos proyectos abordados no son sino dos nudos en las complejas redes intelectuales y comerciales tejidas en el campo cultural argentino por Luís Seoane, a lo largo de su prolífica trayectoria editorial.

\section{REFERENCIAS BIBLIOGRÁFICAS}

Axeitos, Xosé Luis y Xavier Seonne (1994): "Luís Seoane e o libro galego na Arxentina (19371979)", en X. L. Axeitos y X. Seoane (coords.), Luís Seoane e o libro galego na Arxentina [1937-1978]. A Coruña: Deputación Provincial da Coruña, pp. 6-24.

${ }^{3}$ Véase la nota 3.

${ }^{14}$ De ahí que, en carta del 10 de mayo de 1960, Diego Díaz Dorado le escriba a Luis Seoane: "Y pasando a otra cosa, le diré que Citania va sobrellevando las circunstancias económicas particularmente malas, que estamos sufriendo todos aquí". 
De Sagastizábal, Leandro (1995): La edición de libros en la Argentina. Una empresa de cultura. Buenos Aires: Eudeba.

DíAz, Hernán (2012): "Instituciones de la colectividad gallega y redes culturales (1930-1960)", en F. Devoto y R. Villares (eds.), Luis Seoane entre Galicia y la Argentina. Buenos Aires: Biblos-Consello da Cultura Galega, pp. 121-132.

Diego, José Luis de (2006): “1938-1955. La “época de oro’ de la industria editorial”, en J. L. de Diego (dir.), Editores y políticas editoriales en Argentina (1880-2000). Buenos Aires: Fondo de Cultura Económica, pp. 91-123.

Esposito, Fabio (2010): "Los editores españoles en la Argentina: redes comerciales, políticas y culturales entre España y la Argentina (1892-1938)", en C. Altamirano (ed.), Historia de los intelectuales en América Latina. II. Los avatares de la "ciudad letrada" en el siglo XX. Buenos Aires: Katz, pp. 515-536.

Fernández Santiago, Marcelino (2001): “Asociacionismo gallego en Buenos Aires (19361960)”, en X. Núñez Seijas (ed.), La Galicia Austral. La inmigración gallega en la Argentina. Buenos Aires: Biblos, pp. 181-201.

Getino, Octavio (1995): Las industrias culturales en la Argentina. Dimensión económica y políticas públicas. Buenos Aires: Colihue.

Gudiño KIEFFER, Eduardo (2010): La Editorial Losada. Una historia abierta desde 1938. Buenos Aires: Losada.

Larraz, Fernando (2009): "Política y cultura. Biblioteca Contemporánea y Colección Austral, dos modelos de difusión cultural", Orbis Tertius. Revista de Teoría y Crítica Literaria 15 (disponible en: http://www.orbistertius.unlp.edu.ar/article/view/OTv14n15d01/5007).

(2011): "Los exiliados y las colecciones editoriales en Argentina (1938-1954)", en A. Pagni (ed.), El exilio republicano español en México y Argentina. Historia cultural, instituciones literarias, medios. Madrid / Frankfurt: Iberoamericana Vervuert / Bonilla Artigas Editores, pp. 129-144.

MacciucI, Raquel (2011): "Intelectuales españoles en el campo cultural argentino. Francisco Ayala, de Sur a Realidad (1939-1950)", en A. Pagni (ed.), El exilio republicano español en México y Argentina. Historia cultural, instituciones literarias, medios. Madrid / Frankfurt: Iberoamericana Vervuert / Bonilla Artigas Editores, pp. 159-188.

Pérez Rodríguez, María Antonia (2003): Luís Seoane a través da prensa. 1929-1979. Sada: Ediciós do Castro.

(2007): “O labor de Luís Seoane na prensa”, en R. Aneiros Díaz, X. López García, M. Pérez Pereiro y V. F. Freixanes (eds.), Xornalistas con opinión. 20 biografias. Vigo: Consello da Cultura Galega / Galaxia, pp. 323-338.

(2009): "As editoriais no exilio arxentino/Las editoriales en el exilio argentino", Galegos $=$ Gallegos 7, pp. 110-118.

(2013): "Nova 1942-1947: una editorial de exiliados gallegos en Argentina", en A. Santana (coord.), Setenta años de Cuadernos Americanos. México: Universidad Autónoma, pp. 119-134.

Pochat, María Teresa (1991): "Editores y editoriales”, en N. Sánchez-Albornoz (comp.), El destierro español en América. Un trasvase cultural. Madrid: Siruela / Sociedad Estatal Quinto Centenario / Instituto de Cooperación Iberoamericano, pp. 163-176.

RIVERA, Jorge B. (1998): El escritor y la industria cultural. Buenos Aires: Atuel. 
Rodino Lalín, Hugo (1989): “As editoriais galegas en Bós Aires”, Revista do Comisión Galega do Quinto Centenario 1, pp. 49-71.

(1991): “Asociacionismo gallego en Buenos Aires", en H. Clementi (ed.), Inmigración española en la Argentina (Seminario 1990). Buenos Aires: Oficina Cultural de la Embajada de España, pp. 289-314.

SAÍtTA, Sylvia (2004): "Introducción”, en S. Saítta (dir.), Historia crítica de la literatura argentina. Vol. 9. El oficio se afirma. Buenos Aires: Emecé, pp. 7-15.

Schwarzstein, Dora (2001): Entre Franco y Perón. Memoria e identidad del exilio republicano español en Argentina. Barcelona: Crítica.

SeOAne, Luís (1989): Galicia emigrante (1954-1971). Escolma de textos da audición radial de Luís Seoane. Sada: Ediciós do Castro.

ZuletA, Emilia de (1991): "Los exiliados españoles en revistas literarias argentinas", en N. Sánchez-Albornoz (comp.), El destierro español en América. Un trasvase cultural. Madrid: Siruela-Sociedad Estatal Quinto Centenario-Instituto de Cooperación Iberoamericano, pp. 184-198.

(1999): Españoles en la Argentina. El exilio literario de 1936. Buenos Aires: Atril. 